\title{
Diet and Breast Cancer Risk Reduction
}

\author{
Eleni Linos, MD, MPH, and Walter C. Willett, MD, DrPH, Boston, Massachusetts
}

\section{Key Words}

Breast cancer, diet, alcohol, soy, meat, adolescence, obesity

\begin{abstract}
The association between diet and breast cancer risk has been investigated extensively and has led to some recommendations for prevention. Research suggests that maintaining a healthy weight may reduce the risk for breast cancer after menopause. Additionally, alcohol increases the risk for breast cancer even at moderate levels of intake, and women who drink alcohol also should take sufficient folate, which can mitigate this excess risk. Interesting questions for future research include the role of soy products, red meat, energy balance, and vitamin $D$, with particular attention to timing of exposure in early life. Breast cancer is a heterogeneous disease, and dietary factors may differentially affect certain breast cancer subtypes; future studies should therefore attempt to characterize associations according to tumor characteristics. (JNCCN 2007;5:809-816)
\end{abstract}

Although family history and genetics play important roles in the risk for breast cancer, evidence from migration studies $^{1}$ and global trends of rising incidence ${ }^{2}$ indicate that environmental factors also contribute substantially. Dietary factors are among the few modifiable components of breast cancer risk. What people eat could influence the development of cancer through energy balance or diet quality, meaning the composition of their meals. Possible mechanisms include the ingestion of chemicals in foods that are directly mutagenic, affect the metabolism of mutagens, or prevent DNA repair. Diet also could influence the progression of cancer through effects on hormone levels ${ }^{3}$ or growth factors.

However, despite extensive research, only a few clear associations between dietary factors and breast cancer

From the Departments of Nutrition and Epidemiology, Harvard School of Public Health, Boston, Massachusetts.

Submitted April 11, 2007; accepted for publication April 25, 2007.

This research was supported by the National Cancer Institute training grant R25 CA098566.

Correspondence: Eleni Linos, MD, MPH, Channing Laboratory,

Department of Medicine, Brigham and Women's Hospital, and

Harvard Medical School, 181 Longwood Avenue, Boston, MA

02115. E-mail: elinos@hsph.harvard.edu incidence have been established. This could be because breast cancer is a heterogeneous disease with subtypes that may each have distinct etiologies, and that dietary risk factors differ for breast cancer subgroups. Furthermore, diet in early life may matter most because of increased mammary susceptibility to carcinogens during this period, and this has been studied minimally.

The scientific evidence relating individual foods and nutrients to risk for breast cancer was summarized recently. ${ }^{4}$ This review discusses how knowledge of established dietary risk factors for breast cancer, such as overweight and alcohol intake, might be useful in prevention. Targets for future research are identified and the role of diet in early life and among subgroups of the population with differing susceptibility profiles is discussed.

\section{Overweight and Obesity}

Although obese adults are at higher risk for many chronic diseases and premature death, ${ }^{5}$ the relationship of body mass index (BMI) to breast cancer incidence is more complex. Age and menopausal status modify the effect of overweight on the development of this disease. Specifically, women with higher BMI are at lower risk for premenopausal cancer, whereas being overweight after menopause increases the risk for postmenopausal cancer. ${ }^{6-8}$ This may be mediated by hormonal mechanisms, which are discussed later.

\section{Postmenopausal Breast Cancer}

Weight gain during adult life ( $\geq 18$ years $)^{7}$ and overweight ${ }^{8}$ are associated with increased risk for breast cancer after menopause. Aromatization of adrenal androgens in adipose tissue generates estrogens, and thus circulating estrogen levels, are much higher in obese postmenopausal women compared with leaner women. ${ }^{9}$ Moreover, sex hormone binding globulin (SHBG) levels are lower in overweight women, resulting in more bioavailable estrogen in the circulation. ${ }^{10}$ Because plasma estrogens are known to contribute to breast cancer, ${ }^{11,12}$ higher 
concentrations after menopause may increase the chances of developing this disease. Losing weight after menopause can reduce circulating estrogens and increase $\mathrm{SHBG},{ }^{13,14}$ making weight loss a plausible target for risk reduction, especially for women who are not using postmenopausal hormone therapy.

Evidence from the Pooling Project of Prospective Studies on Diet and Cancer (Pooling Project) suggests that postmenopausal women with a BMI of $28 \mathrm{~kg} / \mathrm{m}^{2}$ or higher are $26 \%$ more likely to develop breast cancer than lean women (95\% confidence interval [CI], $9 \%-46 \%),{ }^{8}$ although the risk did not increase as BMI exceeded $28 \mathrm{~kg} / \mathrm{m}^{2}$. Moreover, gaining weight in adulthood greatly increases breast cancer risk..$^{15}$ Estimates from a prospective observational study of 121,701 women in the Nurses Health Study (NHS) indicate that almost $15 \%$ of breast cancers were attributable to weight gain in adulthood (95\% CI, 12.8-17.4)..15

Worth noting is that excess body fat and weight gain are stronger risk factors for postmenopausal breast cancer among women who have never used postmenopausal hormone replacement therapy (HRT; Figure 1). ${ }^{7,8}$ One explanation is that high circulating hormone levels caused by exogenous estrogens could mask the effects of estrogens produced by excess fat tissue. However, because HRT use is declining, the relative contribution of obesity could become even more pronounced in the future.

The effect of weight loss on reducing postmenopausal cancer risk has been examined in prospec-

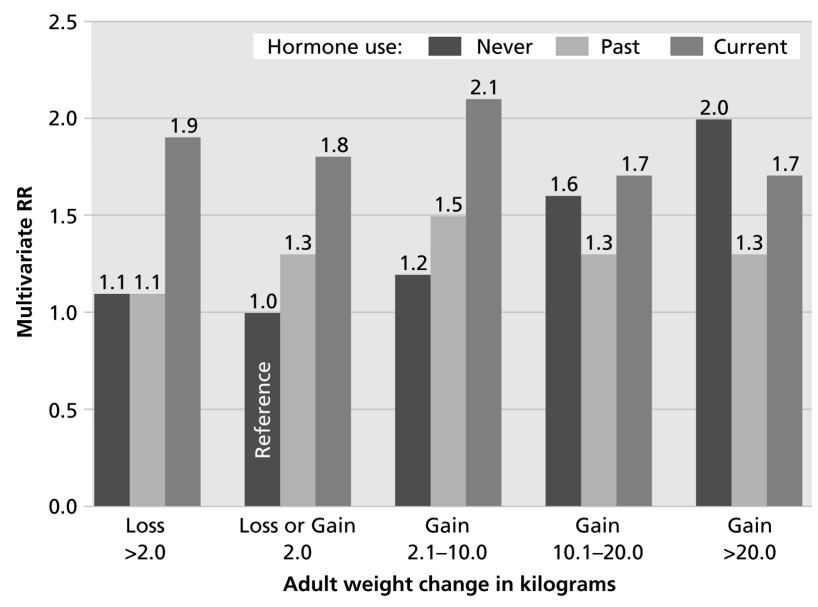

Figure 1 Multivariate adjusted relative risk (RR) of breast cancer according to adult weight change and hormone use.

Adapted from Huang Z, Hankinson SE, Colditz GA, et al. Dual effects of weight and weight gain on breast cancer risk. JAMA 1997;278:1410.

Copyright (c) 1997, American Medical Association. All Rights reserved. tive observational studies. ${ }^{15,16}$ Results from the Iowa Women's Study suggest that maintaining weight in adulthood, as opposed to the usual pattern of gaining weight, is protective for postmenopausal cancer. ${ }^{16} \mathrm{In}$ the NHS cohort, which included 4393 cases of invasive breast cancer, women who lost $10 \mathrm{~kg}$ or more after menopause, and maintained this weight loss, halved their risk for breast cancer (relative risk [RR], 0.43; 95\% CI, 0.21-0.86; Figure 2). Regular physical activity also is associated with a $20 \%$ to $40 \%$ reduction in breast cancer risk, ${ }^{17-20}$ and this benefit persists regardless of weight status, parity, family history, or HRT. Therefore, women can decrease their risk for breast cancer after menopause by maintaining a healthy weight, or losing excess weight that was gained before menopause, and exercising regularly.

\section{Premenopausal Breast Cancer}

Contrary to the findings for postmenopausal cancer, overweight women seem to have a lower risk for breast cancer before menopause. ${ }^{7,8}$ Although exact mechanisms are not clear, one hypothesis is that obesity can cause anovulation and, in the extreme, reduced hormonal cycling and reduced total hormone exposure. Severe underweight can also cause anovulation and is associated with decreased risk for breast cancer, possibly through a similar pathway. ${ }^{21}$ In addition, underweight in premenopausal women may be correlated with other hormonal or growth factors related to breast cancer risk. Elevated insulin-like growth factor 1 (IGF1) may increase premenopausal breast cancer risk, ${ }^{22,23}$ and recent findings suggest that IGF-1 and IGF binding protein 1 levels are significantly higher in women who were leaner in childhood and adolescence (Schernhammer et al., unpublished data). Although based on these observations, increases in body weight

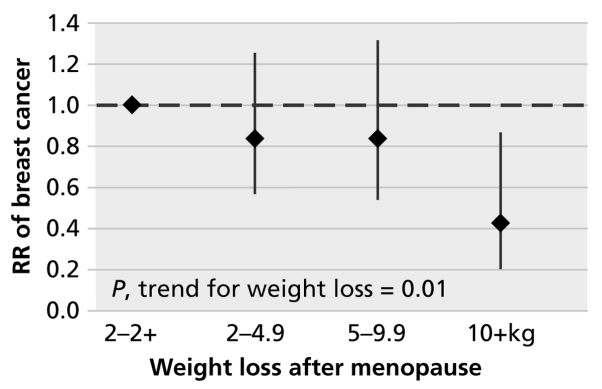

Figure 2 Relative risk (RR) of breast cancer according to sustained weight loss after menopause.

Adapted from Eliassen AH, Colditz GA, Rosner B, et al. Adult weight change and risk of postmenopausal breast cancer. JAMA 2006;296:198. Copyright (C) 2006, American Medical Association. All Rights reserved. 
early in adult life may lead to reductions in risk for premenopausal breast cancer; this would not be advised because of the increased risks for cardiovascular disease and diabetes and the development of breast cancer after menopause.

\section{Alcohol}

Alcohol consumption consistently predicts higher breast cancer rates in epidemiologic studies. Experimental studies in humans show a link between alcohol consumption and elevated plasma estrogens, ${ }^{9}$ making this a pathway through which alcohol may impact cancer risk. Other hypothesized mechanisms include increased solubility of carcinogens, interference with folate metabolism ${ }^{24}$ greater oxidative stress, and mutagenic effects of acetaldehyde, the primary metabolite of alchol..$^{25,26}$

The Pooling Project analysis reported a 9\% increase in breast cancer risk for every additional $10 \mathrm{~g}$ of alcohol per day $(95 \% \mathrm{CI}, 4 \%-13 \%) .{ }^{27}$ This association exists for beer, wine, and liquor separately. Notably, even a moderate intake as low as 4 glasses of wine per week is related to elevated breast cancer risk, especially among women who are postmenopausal and have hormone-sensitive tumours. ${ }^{28,29}$

Fortunately, high dietary intake of folic acid may reduce this excess risk. ${ }^{30}$ Analyses of plasma folic acid confirm this mitigating effect, which is most pronounced in women who consume at least 1 drink per day. ${ }^{31}$ Therefore, women who drink alcohol may benefit from a multivitamin containing folate to lessen their risk for breast cancer.

\section{Foods and Nutrients}

Numerous observational studies have examined associations between specific foods, macronutrients, and micronutrients consumed in adulthood in relation to breast cancer, and their results have been summarized elsewhere $^{32-40}$ (Table 1). Although no overall clear messages for prevention arise from these studies, important questions remain regarding 1) specific foods and nutrients, including red meat, soy, and vitamin $\mathrm{D} ; 2$ ) the timing of dietary exposures; and 3) the impact of food constituents on subtypes of cancer and susceptible groups of the population. These questions, which are important areas for future research, are described in the following sections.

\begin{tabular}{|c|c|c|c|}
\hline $\begin{array}{l}\text { Dietary } \\
\text { Component }\end{array}$ & $\begin{array}{l}\text { Summary } \\
\text { Reference }\end{array}$ & $\begin{array}{l}\text { Strength of } \\
\text { Evidence }\end{array}$ & $\begin{array}{l}\text { Overall } \\
\text { Effect }\end{array}$ \\
\hline Total fat & Smith-Warner et al. ${ }^{33}$ & $* * *$ & $\Leftrightarrow$ \\
\hline Type of fat & Smith-Warner et al. ${ }^{33}$ & $* * *$ & $\Leftrightarrow$ \\
\hline $\begin{array}{l}\text { Total } \\
\text { carbohydrate }\end{array}$ & Cho et al. ${ }^{34}$ & $* * *$ & $\Leftrightarrow$ \\
\hline $\begin{array}{l}\text { Carbohydrate } \\
\text { quality }\end{array}$ & Jonas et al. ${ }^{35}$ & $* * *$ & $\Leftrightarrow$ \\
\hline Fiber & Holmes et al. ${ }^{36}$ & $* * *$ & $\Leftrightarrow$ \\
\hline Red meat $^{\dagger}$ & $\begin{array}{l}\text { Cho et al., }{ }^{49} \\
\text { Missmer et al. }{ }^{51}\end{array}$ & * & $\Uparrow$ \\
\hline Dairy & Missmer et al..$^{51}$ & ** & $\Leftrightarrow$ \\
\hline $\begin{array}{l}\text { Fruits and } \\
\text { vegetables }\end{array}$ & Smith-Warner et al. ${ }^{37}$ & $* * *$ & $\Leftrightarrow$ \\
\hline Soy & Trock et al. ${ }^{56}$ & * & $\Downarrow$ \\
\hline Caffeine & Michels et al. ${ }^{38}$ & $* *$ & $\Leftrightarrow$ \\
\hline Alcohol & Smith-Warner et al. ${ }^{27}$ & $* * *$ & $\Uparrow$ \\
\hline Vitamin D & Shin et al..$^{39}$ & ** & $\Downarrow$ \\
\hline $\begin{array}{l}\text { Vitamins } \\
\text { E, C, A }\end{array}$ & Holmes and Willett ${ }^{64}$ & ** & $\Leftrightarrow$ \\
\hline Folate el al. ${ }^{\ddagger}$ & $\begin{array}{l}\text { Zhang et al.., } \\
\text { Larsson et al. }{ }^{30}\end{array}$ & ** & $\Downarrow$ \\
\hline Carotenoids & Tamimi et al. ${ }^{65}$ & ** & $\Downarrow$ \\
\hline
\end{tabular}

Scale is $(* * *)$ strong evidence to $(*)$ weak evidence.

${ }^{\dagger}$ Especially for premenopausal cancer.

${ }^{\ddagger}$ Among women who drink alcohol regularly.

\section{Red Meat}

Red meat could be a risk factor for certain types of breast cancer, but further studies are needed to confirm this hypothesis. One reason scientists suspect that red meat intake could cause cancer is that heterocyclic amines created during the high-temperature cooking of meat are estrogenic ${ }^{41,42}$ and show some mammary-specific carcinogenic activity in vitro. ${ }^{42,43}$ A nested casecontrol study within the Iowa Women's Health Study cohort showed that regular consumption of well-done and fried meats was associated with a more than 4-fold increase in breast cancer risk (odds ratio [OR], 4.62; 95\% CI, 1.36-15.70) compared with consumption of meat cooked medium or rare. ${ }^{44} \mathrm{~A}$ direct relationship between well-done, deep-fried animal foods and cancer also was seen in a large case-control study from Shanghai (highest to lowest quintile OR, 1.92; $95 \%$ CI, 1.30-2.83)..$^{45}$ In a prospective cohort study from Finland, risk for breast cancer was $80 \%$ higher in those consuming fried meat (highest vs. lowest tertile RR, 
Linos and Willett

1.80; 95\% CI, 1.03-3.16). ${ }^{46}$ Consumption of meat may impact breast cancer risk through other mechanisms including high iron content. Dietary iron enhances estrogen carcinogenicity in rodents, possibly by promoting free radical damage to DNA. ${ }^{47}$ Moreover, exogenous hormones used for growth stimulation of cattle in the United States might persist in commercially available meat and promote tumor growth. ${ }^{48}$ The plausibility of a hormonally-mediated effect is heightened by the finding that the association between red meat and risk for premenopausal breast cancer seems to be limited to estrogen receptor-positive cases. ${ }^{49}$

Adult red meat intake has been reported to increase breast cancer risk, but findings from observational studies have not been consistent ${ }^{50}$ and no significant effect of meat on overall breast cancer was observed in the Pooling Project. ${ }^{51}$ However, recently 2 large prospective studies found elevated breast cancer risk was associated with higher meat consumption. ${ }^{49,52}$ In the NHS II analysis, including 1021 premenopausal cases, Cho et al. ${ }^{49}$ found an elevated risk, especially among estrogen receptor-and progesterone receptor-positive cancers ( $\mathrm{RR}, 1.97 ; \mathrm{CI}, 1.35-2.88)$, in diets consisting of more than 1.5 servings of red meat per day compared with those consisting of 3 or fewer servings per week. These findings, considered together with the biologic pathways discussed earlier, identify red meat consumption as a possible risk factor for hormone-sensitive breast cancer.

\section{Soy}

Soy, traditionally an Asian food, has become a frequent part of the Western diet, and its effect on breast cancer risk continues to be investigated extensively. The isoflavones present in soy are structurally similar to estrogen and can bind estrogen receptors. Soy derivatives can slow cancer cell proliferation in vitro and demonstrate anti-neoplastic properties in some animal models. ${ }^{53}$ However, other experiments suggest these compounds have proestrogenic, tumor-promoting actions, ${ }^{54,55}$ leading to concern regarding their use in women with a high risk for breast cancer.

In a meta-analysis of observational studies, Trock et al..$^{56}$ found a modest apparent protective effect of adult soy intake on breast cancer; however, the authors were cautious in their interpretation of this finding because of concerns about the validity of exposure assessment and potential recall bias in some studies. Case-control studies examining soy consumption during childhood and adolescence have suggested protective effects among Asian women. ${ }^{57,58}$ Likewise, a large population-based case-control study in Canada recently confirmed that phytoestrogens consumed in adolescence among non-Asian women had an inverse, dose-response association with breast cancer $(\mathrm{OR}$, $0.71 ; 95 \% \mathrm{CI}, 0.62-0.82 ; \mathrm{P}<.001$, comparing highest to lowest quartiles). ${ }^{59} \mathrm{~A}$ workshop with the goal of synthesizing the scientific data on this controversial subject concluded that further research on the effects of isoflavones at the cellular level is needed to fully evaluate any potential benefit of soy in women at high risk for breast cancer. ${ }^{60}$

\section{Vitamin D and Carotenoids}

Although mechanistic data are limited, recent epidemiologic findings suggest an inverse association between vitamin D and breast cancer. Within the NHS, higher vitamin $\mathrm{D}$ consumption was associated with lower risk for breast cancer, especially among premenopausal women (RR, 0.72; 95\% CI, 0.55-0.94, comparing $>500 \mathrm{vs.} \leq 150 \mathrm{IU} / \mathrm{d})$. In addition, plasma vitamin $\mathrm{D}$ levels were inversely related to breast cancer in this population ${ }^{61}$ and a dose-response relationship of elevated serum vitamin D intake and lower breast cancer was noted in a pooled analysis (RR from lowest to highest quintiles, 1.00, 0.90, 0.70, 0.70, and $0.50 ; P<.001) .{ }^{62}$ Furthermore, women with the ff FOK1 polymorphism, which results in a less active vitamin D receptor, may be at higher risk for breast cancer. $^{63}$ These findings suggest a protective role of vitamin $\mathrm{D}$ in breast cancer development; however, further studies are needed to establish the relative importance of different dietary sources of vitamin D and the particular period in life when this association is strongest and could be important for prevention.

Studies on the effects of dietary carotenoids have been inconclusive, with protective effects noted mainly for premenopausal cancers.${ }^{64}$ However, more consistent associations between high levels of plasma carotenoids and lower risk for breast cancer ${ }^{65-67}$ make this an important area for future research. Of specific interest are the mechanisms involved and whether carotenoids themselves are protective or if they are markers for other beneficial components of fruits and vegetables.

\section{Dietary Fat}

The hypothesis that dietary fat may be a risk factor for breast cancer originated from ecological and case control studies; however, evidence from large prospective 
cohort studies ${ }^{32,68-75}$ and clinical trials ${ }^{76}$ has not supported an important adverse effect of total fat. A nonsignificant decrease in breast cancer risk was observed in the Women's Health Initiative (WHI) trial (RR = $0.91 ; 95 \% \mathrm{CI}, 0.83-1.02$ comparing low to high fat groups). This small reduction in risk, if real, could be explained by the modest weight loss noted in the low fat group. ${ }^{77}$ Low fat dietary interventions have not caused significant weight loss in other trials lasting one year or more ${ }^{78}$ suggesting that the WHI weight loss was probably due to the intensity of dietary intervention rather than a change in diet composition. The established benefit of replacing saturated and trans fats with unsaturated fats for cardiovascular disease prevention $^{79}$ should guide our recommendations for a healthy diet.

\section{Diet in Early Life}

Some scientists hypothesize that exposures in early life may be particularly important in predicting later breast cancer risk. Evidence from animal studies suggests that mammary tissue is especially sensitive to carcinogenic exposures that occur after menarche and before first pregnancy. ${ }^{80,81}$ Historic analyses show the importance of time of exposure in predicting breast cancer risk in humans. Japanese women who migrated to Hawaii as adults did not experience higher risks for breast cancer, whereas their daughters and granddaughters did.$^{82}$ Furthermore, breast cancer risk increased dramatically among women aged 20 years or younger but not among those older than 35 years at the Hiroshima and Nagasaki bombings. ${ }^{83,84}$ Finally, lower rates of breast cancer were noted among Norwegian women who were adolescents during the food shortages of World War II, a period marked by low red meat, diary, and fat availability. ${ }^{85}$ These findings imply that environmental exposures during adolescence significantly impact breast cancer risk.

Plausible biologic explanations exist for this hypothesis. Breast tissue develops during puberty, undergoing regular hormone-dependent cell division at each menstrual cycle. However, the final histologic architecture of mammary ducts, including terminal differentiation of the end buds, is attained during lactation after first pregnancy. This window of undifferentiated cell turnover may translate into a period of susceptibility and increased sensitivity to environmental risk factors. Moreover, nutrition in early life, even in utero, affects birth weight, height, and age at menarche, all of which are established breast cancer risk factors. Therefore, the diets of children and adolescents and how they predict later risk for breast cancer have been of particular scientific interest.

Retrospective case-control studies assessing dietary exposures in early life rely on participants' memory of their diet many years earlier and may be subject to recall bias if breast cancer patients report childhood diet differently to healthy controls. Nevertheless, these studies provide important preliminary information that identifies possible research targets. Casecontrol studies of diet in adolescence have reported decreased risk for cancer with diets high in fat from dairy foods, ${ }^{86}$ milk, and vitamin $\mathrm{D},{ }^{87}$ an increased risk with frequent consumption of meat with visible fat, ${ }^{88}$ and a borderline effect for high-fat meats. ${ }^{89}$ An inverse association between high consumption of vegetable fat and vitamin E was noted in the NHS II study, which used a validated food frequency questionnaire ${ }^{90,91}$ to assess the diet of 45,947 nurses while they were in high school. ${ }^{22}$ This study showed a positive association between the consumption of foods with a high glycemic index and the incidence of breast cancer. High soy and phytoestrogen consumption in adolescence are related to lower breast cancer rates in several case-control studies. ${ }^{57-59}$ If accumulating evidence continues to show that some foods and nutrients impact breast cancer risk when consumed during early life rather than in adulthood, more subtle questions will need to be considered, such as 1) timing, or what the precise chronologic bounds are of this susceptibility period; 2) impact, or how important diet is in early life relative to other established risk factors for breast cancer; and 3) policy, whether dietary recommendations are necessary and to whom they should be directed.

\section{Subgroup Effects}

Breast cancer is a common disease with a diverse profile. It can present throughout adulthood, with a range of clinical features, histologic characteristics, chromosomal mutations, and severity profiles. The etiology of this heterogeneous disease may differ across population groups or tumor characteristics. Therefore, the diet may have a stronger effect on certain subgroups or selectively affect some types of breast cancer. For example, high BMI is only a risk factor for breast cancer among postmenopausal women. 
Linos and Willett

Furthermore, red meat intake may selectively increase the risk for hormone-sensitive cancers, whereas a prudent diet seemed to be protective only for estrogen receptor-negative cancers. ${ }^{93}$ A recent study from Sweden noted that women with aggressive high-grade tumors more frequently reported low-fat, low-energy diets. ${ }^{94}$ Identifying these relationships is important in developing prevention strategies for high-risk groups and to better understand mechanisms involved in the pathogenesis of this diverse group of diseases.

Studies of gene-diet interactions can theoretically show the principle of interaction between characteristics of individuals and diet. For example, in a case-control study of SHBG gene polymorphisms, a significant increase in SHBG levels with increasing isoflavones was seen only among those with the D356N polymorphism associated with reduced SHBG clearance. ${ }^{95}$ Similarly, in a case-control study of more than 2000 women, ${ }^{96}$ an apparent protective effect of high fruit intake was noted only among those with a high-activity antioxidant catalase enzyme polymorphism. Among women with BRCA1 and BRCA2 tumor suppressor gene mutations, total energy intake and weight gain in adulthood was associated with a higher risk for breast cancer independent of BMI or physical activity. ${ }^{97}$

Although nutrigenomics has potential for tailored public health interventions, very few studies have sufficient statistical power to detect interactions, making interpretation of results from gene-environment studies difficult. For example, the presence of vitamin D receptor polymorphism has been associated with breast cancer, ${ }^{63}$ although whether this association is modified by dietary or plasma vitamin D is unclear. Similarly, the methylenetetrahydrofolate reductase receptor was not associated with breast cancer according to a recent metaanalysis, ${ }^{98}$ although its role regarding alcohol-folate interaction deserves further study. Furthermore, any finding will need replication because many falsepositive interactions are likely to be reported. Before we can develop selective dietary recommendations for breast cancer prevention, concrete scientific evidence is needed through large, prospective studies, including repeated measures and accurate exposure assessment.

\section{Conclusions}

Maintaining a healthy body weight and regular exercise have tremendous health benefits, including a probable reduction in breast cancer risk after menopause. Although drinking alcohol is linked to higher risk for breast cancer even at modest levels of consumption, women who drink may decrease their risk by taking sufficient folate. Avoiding high consumption of red meat during the premenopausal years is likely to reduce risk for coronary heart disease, and this may also reduce risk for breast cancer. Although much is already known about the dietary predictors of breast cancer, promising areas for future research include effects of soy, vitamin D, and carotenoids with particular attention to timing of exposure and tumor characteristics.

\section{References}

1. Stanford JL, Herrinton LJ, Schwartz SM, et al. Breast cancer incidence in Asian migrants to the United States and their descendants. Epidemiology 1995;6:181-183.

2. Bray F, McCarron P, Parkin DM. The changing global patterns of female breast cancer incidence and mortality. Breast Cancer Res 2004;6:229-239.

3. Kendall A, Folkerd EJ, Dowsett M. Influences on circulating oestrogens in postmenopausal women: relationship with breast cancer. J Steroid Biochem Mol Biol 2007;103:99-109.

4. Linos E, Holmes MD, Willett WC. Diet and breast cancer. Curr Oncol Rep 2007;9:31-41.

5. Hu FB, Willett WC, Li T, et al. Adiposity as compared with physical activity in predicting mortality among women. N Engl J Med 2004;351:2694-2703.

6. Calle EE, Rodriguez C, Walker-Thurmond K, Thun MJ. Overweight, obesity, and mortality from cancer in a prospectively studied cohort of U.S. adults. JAMA 2003;348:1625-1638.

7. Huang Z, Hankinson SE, Colditz GA, et al. Dual effects of weight and weight gain on breast cancer risk. JAMA 1997;278:1407-1411.

8. van den Brandt PA, Spiegelman D, Yaun SS, et al. Pooled analysis of prospective cohort studies on height, weight, and breast cancer risk. Am J Epidemiol 2000;152:514-527.

9. Hankinson SE, Willett WC, Manson JE, et al. Alcohol, height, and adiposity in relation to estrogen and prolactin levels in postmenopausal women. J Natl Cancer Inst 1995;87:1297-1302.

10. Newcomb P, Klein R, Klein B, et al. Association of dietary and lifestyle factors with sex hormones in postmenopausal women. Epidemiology 1995;6:318-321.

11. Key T, Appleby P, Barnes I, et al. Endogenous sex hormones and breast cancer in postmenopausal women: reanalysis of nine prospective studies. J Natl Cancer Inst 2002;94:606-616.

12. Thomas H, Reeves G, Key T. Endogenous estrogen and postmenopausal breast cancer: a quantitative review. Cancer Causes Control 1997;8:922-928.

13. de Waard F, Poortman J, de Pedro-Alvarez Ferrero M, Baanders-van Halewijh EA. Weight reduction and oestrogen excretion in obese post-menopausal women. Maturitas 1982;4:155-162.

14. Enriori CL, Orsini W, del Carmen Cremona M, et al. Decrease of circulating level of SHBG in postmenopausal obese women as a risk factor in breast cancer: reversible effect of weight loss. Gynecol Oncol 1986;23:77-86. 
15. Eliassen AH, Colditz GA, Rosner B, et al. Adult weight change and risk of postmenopausal breast cancer. JAMA 2006;296:193-201.

16. Harvie M, Howell A, Vierkant RA, et al. Association of gain and loss of weight before and after menopause with risk of postmenopausal breast cancer in the Iowa women's health study. Cancer Epidemiol Biomarkers Prev 2005;14:656-661.

17. Bianchini F, Kaaks R, Vainio H. Weight control and physical activity in cancer prevention. Obes Rev 2002;3:5-8.

18. Tehard B, Friedenreich CM, Oppert JM, et al. Effect of physical activity on women at increased risk of breast cancer: results from the E3N cohort study. Cancer Epidemiol Biomarkers Prev 2006;15:57-64.

19. Bianchini $F$, Kaaks $R$, Vainio H. Weight control and physical activity in cancer prevention. Obes Rev 2002;3:5-8.

20. Tehard B, Friedenreich CM, Oppert JM, et al. Effect of physical activity on women at increased risk of breast cancer: results from the E3N cohort study. Cancer Epidemiol Biomarkers Prev 2006;15:57-64.

21. Michels KB, Ekbom A. Caloric restriction and incidence of breast cancer. JAMA 2004;291:1226-1230.

22. Hankinson SE, Willett WC, Colditz GA, et al. Circulating concentrations of insulin-like growth factor-I and risk of breast cancer. Lancet 1998;351:1393-1396.

23. Renehan AG, Harvie M, Howell A. Insulin-like growth factor (IGF)I, IGF binding protein-3, and breast cancer risk: eight years on. Endocr Relat Cancer 2006;13:273-278.

24. Weir DG, McGing PG, Scott JM. Folate metabolism, the enterohepatic circulation and alcohol. Biochem Pharmacol 1985;34:1-7.

25. Castro GD, de Castro CR, Maciel ME, et al. Ethanol-induced oxidative stress and acetaldehyde formation in rat mammary tissue: potential factors involved in alcohol drinking promotion of breast cancer. Toxicology 2006;219:208-219.

26. Garro AJ, Lieber CS. Alcohol and cancer. Annu Rev Pharmacol Toxicol 1990;30:219-249.

27. Smith-Warner SA, Spiegelman D, Yaun SS, et al. Alcohol and breast cancer in women: a pooled analysis of cohort studies. JAMA 1998;279:535-540.

28. Chen WY, Willett WC, Rosner B, Colditz GA. Moderate alcohol consumption and breast cancer [abstract]. J Clin Oncol 2005;23: (Suppl 1)7s. Abstract 515.

29. Zhang SM, Lee IM, Manson JE, et al. Alcohol consumption and breast cancer risk in the Women's Health Study. Am J Epidemiol 2007;165:667-676.

30. Zhang S, Hunter DJ, Hankinson SE, et al. A prospective study of folate intake and the risk of breast cancer. JAMA 1999;281:1632-1637.

31. Zhang SM, Willett WC, Selhub J, et al. Plasma folate, vitamin B6, vitamin B12, homocysteine, and risk of breast cancer. J Natl Cancer Inst 2003;95:373-380.

32. Velie E, Kulldorff M, Schairer C, et al. Dietary fat, fat subtypes, and breast cancer in postmenopausal women: a prospective cohort study. J Natl Cancer Inst 2000;92:833-839.

33. Smith-Warner SA, Spiegelman D, Adami HO, et al. Types of dietary fat and breast cancer: a pooled analysis of cohort studies. Int J Cancer 2001;92:767-774.

34. Cho E, Spiegelman D, Hunter DJ, et al. Premenopausal dietary carbohydrate, glycemic index, glycemic load, and fiber in relation to risk of breast cancer. Cancer Epidemiol Biomarkers Prev 2003;12:1153-1158.

35. Jonas CR, McCullough ML, Teras LR, et al. Dietary glycemic index, glycemic load, and risk of incident breast cancer in postmenopausal women. Cancer Epidemiol Biomarkers Prev 2003;12:573-577.

36. Holmes MD, Liu S, Hankinson SE, et al. Dietary carbohydrates, fiber, and breast cancer risk. Am J Epidemiol 2004;159:732-739.
37. Smith-Warner SA, Spiegelman D, Yaun SS, et al. Intake of fruits and vegetables and risk of breast cancer: a pooled analysis of cohort studies. JAMA 2001;285:769-776.

38. Michels KB, Holmberg L, Bergkvist L, et al. Coffee, tea, and caffeine consumption and breast cancer incidence in a cohort of Swedish women. Ann Epidemiol 2002;12:21-26.

39. Shin $\mathrm{MH}$, Holmes MD, Hankinson SE, et al. Intake of dairy products, calcium, and vitamin d and risk of breast cancer. J Natl Cancer Inst 2002;94:1301-1311.

40. Larsson SC, Giovannucci E, Wolk A. Folate and risk of breast cancer: a meta-analysis. J Natl Cancer Inst 2007;99:64-76.

41. Qiu C, Shan L, Yu M, et al. Steroid hormone receptor expression and proliferation in rat mammary gland carcinomas induced by 2 -amino1-methyl-6-phenylimidazo[4,5-b]pyridine. Carcinogenesis 2005;26: 763-769.

42. Lauber SN, Ali S, Gooderham NJ. The cooked food derived carcinogen 2-amino-1-methyl-6-phenylimidazo[4,5-b] pyridine is a potent oestrogen: a mechanistic basis for its tissue-specific carcinogenicity. Carcinogenesis 2004;25:2509-2517.

43. Bennion BJ, Cosman M, Lightstone FC, et al. PhIP carcinogenicity in breast cancer: computational and experimental evidence for competitive interactions with human estrogen receptor. Chem Res Toxicol 2005;18:1528-1536.

44. Zheng W, Gustafson DR, Sinha R, et al. Well-done meat intake and the risk of breast cancer. J Natl Cancer Inst 1998;90:1724-1729.

45. Dai $\mathrm{Q}$, Shu $\mathrm{XO}$, Jin F, et al. Consumption of animal foods, cooking methods, and risk of breast cancer. Cancer Epidemiol Biomarkers Prev 2002;11:801-808.

46. Jarvinen R, Knekt P, Seppanen R, et al. Diet and breast cancer risk in a cohort of Finnish women. Cancer Lett 1997;114:251-253.

47. Wyllie S, Liehr JG. Enhancement of estrogen-induced renal tumorigenesis in hamsters by dietary iron. Carcinogenesis 1998;19: 1285-1290.

48. Andersson AM, Skakkebaek NE. Exposure to exogenous estrogens in food: possible impact on human development and health. Eur J Endocrinol 1999;140:477-485.

49. Cho E, Chen WY, Hunter DJ, et al. Red meat intake and risk of breast cancer among premenopausal women. Arch Intern Med 2006;166:2253-2259.

50. Boyd NF, Stone J, Vogt KN, et al. Dietary fat and breast cancer risk revisited: a meta-analysis of the published literature. Br J Cancer 2003;89:1672-1685.

51. Missmer SA, Smith-Warner SA, Spiegelman D, et al. Meat and dairy food consumption and breast cancer: a pooled analysis of cohort studies. Int J Epidemiol 2002;31:78-85.

52. Taylor, Burley VJ, Greenwood DC, et al. Meat consumption and risk of breast cancer in the UK Women's Cohort Study. Br J Cancer 2007;96:1139-1146.

53. Messina MJ, Persky V, Setchell KD, et al. Soy intake and cancer risk: a review of the in vitro and in vivo data. Nutr Cancer 1994;21: $113-131$.

54. Allred CD, Allred KF, Ju YH, et al. Soy diets containing varying amounts of genistein stimulate growth of estrogen-dependent (MCF7) tumors in a dose-dependent manner. Cancer Res 2001;61: 5045-5050.

55. Hsieh CY, Santell RC, Haslam SZ, et al. Estrogenic effects of genistein on the growth of estrogen receptor-positive human breast cancer (MCF-7) cells in vitro and in vivo. Cancer Res 1998;58: 3833-3838.

56. Trock BJ, Hilakivi-Clarke L, Clarke R. Meta-analysis of soy intake and breast cancer risk. J Natl Cancer Inst 2006;98:459-471. 
Linos and Willett

57. Shu XO, Jin F, Dai Q, et al. Soyfood intake during adolescence and subsequent risk of breast cancer among Chinese women. Cancer Epidemiol Biomarkers Prev 2001;10:483-488.

58. Wu AH, Wan P, Hankin J, et al. Adolescent and adult soy intake and risk of breast cancer in Asian-Americans. Carcinogenesis 2002;23:1491-1496.

59. Thanos J, Cotterchio M, Boucher BA, et al. Adolescent dietary phytoestrogen intake and breast cancer risk (Canada). Cancer Causes Control 2006;17:1253-1261.

60. Messina M, McCaskill-Stevens W, Lampe JW. Addressing the soy and breast cancer relationship: review, commentary, and workshop proceedings. J Natl Cancer Inst 2006;98:1275-1284.

61. Bertone-Johnson ER, Chen WY, Holick MF, et al. Plasma 25 hydroxyvitamin D and 1,25-dihydroxyvitamin D and risk of breast cancer. Cancer Epidemiol Biomarkers Prev 2005;14:1991-1997.

62. Garland CF, Gorham ED, Mohr SB, et al. Vitamin D and prevention of breast cancer: pooled analysis. J Steroid Biochem Mol Biol 2007;103:708-711.

63. Chen WY, Bertone-Johnson ER, Hunter DJ, et al. Associations between polymorphisms in the vitamin D receptor and breast cancer risk. Cancer Epidemiol Biomarkers Prev 2005;14:2335-2339.

64. Holmes MD, Willett WC. Does diet affect breast cancer risk? Breast Cancer Res 2004;6:170-178.

65. Tamimi RM, Hankinson SE, Campos H, et al. Plasma carotenoids, retinol, and tocopherols and risk of breast cancer. Am J Epidemiol 2005;161:153-160.

66. Toniolo P, Van Kappel AL, Akhmedkhanov A, et al. Serum carotenoids and breast cancer. Am J Epidemiol 2001;153:1142-1147.

67. Sato R, Helzlsouer KJ, Alberg AJ, et al. Prospective study of carotenoids, tocopherols, and retinoid concentrations and the risk of breast cancer. Cancer Epidemiol Biomarkers Prev 2002;11:451-457.

68. Wolk A, Bergstrom R, Hunter D et al. A prospective study of association of monounsaturated fat and other types of fat with risk of breast cancer. Arch Intern Med 1998;158:41-45.

69. van den Brandt PA, van't Veer P, Goldbohm RA, et al. A prospective cohort study on dietary fat and the risk of postmenopausal breast cancer. Cancer Res 1993;53:75-82.

70. Kushi LH, Sellers TA, Potter JD, et al. Dietary fat and postmenopausal breast cancer. J Natl Cancer Inst 1992;84:1092-1099.

71. Howe GR, Friedenreich CM, Jain M, et al. A cohort study of fat intake and risk of breast cancer. J Natl Cancer Inst 1991;83:336-340.

72. Holmes M, Hunter D, Colditz G, et al. Association of dietary intake of fat and fatty acids with risk of breast cancer. JAMA 1999;281:914-920.

73. Horn-Ross PL, Hoggatt KJ, West DW, et al. Recent diet and breast cancer risk: the California Teachers Study (USA). Cancer Causes Control 2002;13:407-415.

74. $\mathrm{Kim} \mathrm{DH,} \mathrm{Kim} \mathrm{JS,} \mathrm{Ji} \mathrm{YI,} \mathrm{et} \mathrm{al.} \mathrm{Hypermethylation} \mathrm{of} \mathrm{RASSF1A} \mathrm{promoter}$ is associated with the age at starting smoking and a poor prognosis in primary non-small cell lung cancer. Cancer Res 2003;63:3743-3746.

75. Thiebaut AC, Kipnis V, Chang SC, et al. Dietary fat and postmenopausal invasive breast cancer in the National Institutes of Health-AARP Diet and Health Study cohort. J Natl Cancer Inst 2007;99:451-462.

76. Prentice RL, Caan B, Chlebowski RT, et al. Low-fat dietary pattern and risk of invasive breast cancer: the Women's Health Initiative Randomized Controlled Dietary Modification Trial. JAMA 2006;295:629-642.

77. Lagiou P, Trichopoulos D, Adami HO. Low-fat diet and risk of breast cancer. JAMA 2006;296:278; author reply 279.
78. Willett WC, Leibel RL. Dietary fat is not a major determinant of body fat. Am J Med 2002;113(Suppl 9B):47S-59S.

79. Hu FB, Willett WC. Optimal diets for prevention of coronary heart disease. JAMA 2002;288:2569-2578.

80. Russo J, Tay LK, Russo IH. Differentiation of the mammary gland and susceptibility to carcinogenesis. Breast Cancer Res Treat 1982;2:5-73.

81. Ariazi JL, Haag JD, Lindstrom MJ, et al. Mammary glands of sexually immature rats are more susceptible than those of mature rats to the carcinogenic, lethal, and mutagenic effects of $\mathrm{N}$-nitroso- $\mathrm{N}$ methylurea. Mol Carcinog 2005;43:155-164.

82. Ziegler RG, Hoover RN, Pike MC, et al. Migration patterns and breast cancer risk in Asian-American women. J Natl Cancer Inst 1993;85:1819-1827.

83. Land CE, Tokunaga M, Koyama K, et al. Incidence of female breast cancer among atomic bomb survivors, Hiroshima and Nagasaki, 1950-1990. Radiat Res 2003;160:707-717.

84. Land CE. Studies of cancer and radiation dose among atomic bomb survivors. The example of breast cancer. JAMA 1995;274:402-407.

85. Tretli S, Gaard M. Lifestyle changes during adolescence and risk of breast cancer: an ecologic study of the effect of World War II in Norway. Cancer Causes Control 1996;7:507-512.

86. Pryor M, Slattery ML, Robison LM, et al. Adolescent diet and breast cancer in Utah. Cancer Res 1989;49:2161-2167.

87. Knight JA, Lesosky M, Barnett $\mathrm{H}$, et al. Vitamin d and reduced risk of breast cancer: a population-based case-control study. Cancer Epidemiol Biomarkers Prev 2007;16:422-429.

88. Hislop TG, Coldman AJ, Elwood JM, et al. Childhood and recent eating patterns and risk of breast cancer. Cancer Detect Prev 1986;9:47-58.

89. Potischman N, Weiss HA, Swanson CA, et al. Diet during adolescence and risk of breast cancer among young women. J Natl Cancer Inst 1998;90:226-233.

90. Maruti SS, Feskanich D, Rockett HR, et al. Validation of adolescent diet recalled by adults. Epidemiology 2006;17:226-229.

91. Maruti SS, Feskanich D, Colditz GA, et al. Adult recall of adolescent diet: reproducibility and comparison with maternal reporting. Am J Epidemiol 2005;161:89-97.

92. Frazier AL, Li L, Cho E, et al. Adolescent diet and risk of breast cancer. Cancer Causes Control 2004;15:73-82.

93. Fung TT, Hu FB, Holmes MD, et al. Dietary patterns and the risk of postmenopausal breast cancer. Int J Cancer 2005;116:116-121.

94. Borgquist $\mathrm{S}$, Wirfalt $\mathrm{E}$, Jirstrom $\mathrm{K}$, et al. Diet and body constitution in relation to sub-groups of breast cancer defined by tumour grade, proliferation and key cell cycle regulators. Breast Cancer Res 2007;9:R11.

95. Low YL, Dunning AM, Dowsett M, et al. Implications of geneenvironment interaction in studies of gene variants in breast cancer: an example of dietary isoflavones and the $\mathrm{D} 356 \mathrm{~N}$ polymorphism in the sex hormone-binding globulin gene. Cancer Res 2006;66: 8980-8983.

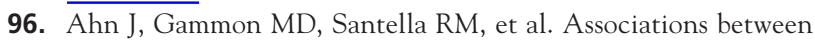
breast cancer risk and the catalase genotype, fruit and vegetable consumption, and supplement use. Am J Epidemiol 2005;162:943-952.

97. Nkondjock A, Robidoux A, Paredes Y, et al. Diet, lifestyle and BRCA-related breast cancer risk among French-Canadians. Breast Cancer Res Treat 2006;98:285-294.

98. Lewis SJ, Harbord RM, Harris R, et al. Meta-analyses of observational and genetic association studies of folate intakes or levels and breast cancer risk. J Natl Cancer Inst 2006;98:1607-1622. 